\title{
Synthesis of Hydrotalcite-Supported CdTe Semiconductor Nanocrystals for Electrochemical Detection of Ciprofloxacin
}

\author{
Sanny W. M. M. Carvalho, ${ }^{a}$ Tiago B. S. Santana, ${ }^{b}$ Charlene R. S. Matos, ${ }^{a}$ Luiz P. Costa,${ }^{c}$ \\ Eliana M. Sussuchi ${ }^{\oplus a}$ and Iara F. Gimenez ${ }^{\odot *, a}$ \\ aPrograma de Pós-Graduação em Química, Universidade Federal de Sergipe, \\ Av. Marechal Rondon s/n, 49100-000 São Cristóvão-SE, Brazil \\ ${ }^{b}$ Departamento de Farmácia, Universidade Federal de Sergipe, \\ Av. Marechal Rondon s/n, 49100-000 São Cristóvão-SE, Brazil
}

'Programa de Pós-Graduação em Química, Universidade Federal do Amazonas (UFAM), Av. Rodrigo Otávio, 6200, Campus Senator Arthur Virgílio Filho, Setor Norte, Coroado I, 69077-000 Manaus-AM, Brazil

In this work, CdTe quantum dots (QDs) were controllably grown onto the surface of layered double hydroxide (LDH) aiming to develop a sensitive and selective method for the electrochemical detection of ciprofloxacin (CPX). Emission and absorption spectroscopy results as well as high-resolution transmission electron microscopy (HRTEM) images evidenced the formation of LDH/QD hybrid material. Unmodified carbon paste electrodes (CPE) as well as CPE chemically modified (MCPE) with native LDH and with the LDH/QD hybrid were prepared for CPX detection, revealing that MCPE-LDH/QD had the highest sensitivity for the detection of ciprofloxacin. Optimum detection conditions included a modifier dosage of $20 \%$ in MCPE, Britton-Robinson (BR) buffer (pH 6.0) as analytical medium, $300 \mathrm{~s}$ accumulation time and a scanning rate of $20 \mathrm{mV} \mathrm{s}^{-1}$. Linear current versus concentration curve was observed from $2.5 \times 10^{-8}-1.2 \times 10^{-5} \mathrm{~mol} \mathrm{~L}^{-1}$ (coefficient of determination $\left(\mathrm{R}^{2}\right)=0.995$ ), with sensitivity (limit of detection $(\mathrm{LOD})=4.2 \times 10^{-8} \mathrm{~mol} \mathrm{~L}^{-1}$; limit of quantification $(\mathrm{LOQ})=1.3 \times 10^{-7} \mathrm{~mol} \mathrm{~L}^{-1}$ ), precision (relative standard deviation $(\mathrm{RSD})=3.0 \%$ ), accuracy $(94.0 \%)$ and satisfactory selectivity in the presence of $\mathrm{Zn}^{2+}, \mathrm{Fe}^{2+}, \mathrm{Cu}^{2+}$, citric acid and ascorbic acid. Tests of CPX determination in commercial $500 \mathrm{mg}$ ciprofloxacin tablets evidenced the applicability of the method.

Keywords: CdTe, semiconductor nanocrystals, hydrotalcite, ciprofloxacin, cyclic voltammetry

\section{Introduction}

Ciprofloxacin (CPX) is a second-generation fluoroquinolone antibiotic developed by Bayer researchers, widely prescribed for the treatment of gastrointestinal, urinary, respiratory, ocular, bone and cutaneous infections. ${ }^{1,2}$ It is also widely used to prevent and control diseases in agricultural environments. However, owing to both the widespread use and the low biodegradability, fluoroquinolone residues are present in effluents from domestic origin as well as from animal farms, hospitals and pharmaceutical industries. ${ }^{3}$ Animal farm effluents ${ }^{4}$ and family households ${ }^{5}$ usually contain CPX amounts between 5 and $6 \mu \mathrm{g} \mathrm{L}^{-1}$, while raw hospital sewages ${ }^{5}$ may contain

*e-mail: iara.gimenez@gmail.com more than $120 \mu \mathrm{g} \mathrm{L}^{-1}$ and pharmaceutical industries release concentrations around $30 \mathrm{mg} \mathrm{L}^{-1}$.

Distinct harmful effects of the widespread and indiscriminate use of fluoroquinolones can be identified. First, environmental contamination may represent serious threats to ecosystems, as ecological risk assessment has shown that some types of fresh water organisms, particularly cyanobacteria, are strongly sensitive to fluoroquinolones. ${ }^{7}$ On the other hand, long-term, broad or incorrect use and even abuse of antibiotics may lead to development of bacterial resistance to currently used antibiotics. ${ }^{8}$ The development of either mutated DNA-binding proteins or efflux pump mechanism for drugs are considered the main problems associated with the therapeutic use of fluoroquinolones. Finally, as adverse effects are unusual, fluoroquinolones are considered well tolerated. However, 
central nervous system effects, as well as gastrointestinal and allergic reactions are more common with quinolones than with other antimicrobial classes. ${ }^{9}$ The important point is that these effects may also occur in the case of unnoticed long-term ingestion with contaminated food and liquids.

In this context, several analytical methods have been proposed for the determination of CPX, ${ }^{10-12}$ usually looking for alternative, selective and sensitive techniques, as well as other requisites such as easy handling, on-site detection and low cost. Compared to other instrumental methods, electrochemistry fulfils such requirements with the possibility of electrode modification in order to become increasingly sensitive and selective to antibiotics. ${ }^{13,14}$ In this context, different working electrodes have been reported for the detection of ciprofloxacin and here we cite some of the literature reports as illustrative examples, as it was not our aim to present an extensive review of the field. However, CPX detection can be carried out with different techniques (including cyclic voltammetry, differential pulse voltammetry, sweep stripping voltammetry, amperometry), with different types of electrodes (glassy carbon (GCE), $\mathrm{Hg}$, carbon paste, heavily boron doped diamond, among others), also with a wide range of electrode modifiers (multi-walled carbon nanotubes (MWCNT), metal nanoparticles, semiconductor nanocrystals, etc.). In most of the works, the limits of detection (LOD) lie

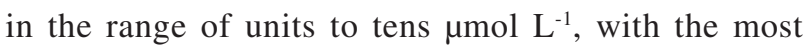
sensitive ones with LOD values below $0.05 \mu \mathrm{mol} \mathrm{L}^{-1}$. For instance, Fotouhi and Alahyari ${ }^{15}$ constructed glassy carbon electrodes coated with multi-walled nanotube films (MWCNT/GCE), which under optimized conditions presented a detection limit of $6.0 \times 10^{-6} \mathrm{~mol} \mathrm{~L}^{-1}$ in the range of $4.0 \times 10^{-5}-0.001 \mathrm{~mol} \mathrm{~L}^{-1}$. In the work described by Garbellini et al., ${ }^{16} \mathrm{CPX}$ was determined with boron-doped diamond (BDD) electrode employing two electrochemical techniques: square-wave voltammetry (SWV) and differential pulse voltammetry (DPV). Analytical curves were obtained for CPX concentrations ranging from $2.5 \times 10^{-6}$ to $5.0 \times 10^{-5} \mathrm{~mol} \mathrm{~L}^{-1}$, for SWV, and from $5.0 \times 10^{-7}$ to $6.0 \times 10^{-5} \mathrm{~mol} \mathrm{~L}^{-1}$, for DPV, with detection limits of $2.46 \times 10^{-6}$ and $4.4 \times 10^{-4} \mathrm{~mol} \mathrm{~L}^{-1}$, respectively. Shan et al. ${ }^{17}$ proposed the determination of CPX using CdS quantum dots (QDs)-modified GCE. A linear relationship was found between the anodic stripping voltammetric response of CdS QDs/GCE and CPX concentration in the range from $1.0 \times 10^{-7}$ to $1.0 \times 10^{-5} \mathrm{~mol} \mathrm{~L}^{-1}$, with a detection limit of $2.2 \times 10^{-8} \mathrm{~mol} \mathrm{~L}^{-1}$. As an alternative to working electrodes, carbon paste electrodes (CPE) produced from graphite powder and agglutinate provide a low cost and faster route for the development of chemically modified electrodes. The stabilization of quantum dots on these electrodes is still a challenge in the electrochemical direct detection of analytes such as CPX.

Owing to their electrochemical activity, very small size, large specific surface area and excellent biocompatibility, CdTe nanocrystals are promising as modifier for carbon paste electrodes. ${ }^{18-20}$ In this context, semiconductor applications in electrochemical sensors rely mostly on the fact that these nanomaterials have high electron transfer efficiency, increasing the rate of transfer processes. ${ }^{21}$ Current works reported in the literature focus on the synthesis of semiconductor nanocrystals in situ in inorganic matrices, as these solids provide a quantum confinement environment, improving the stability toward coalescence processes, ${ }^{22}$ while enabling the nanocrystal application in solid devices. ${ }^{23}$ Moreover, preparation of nanocrystals supported onto solid matrices may increase the exposed area of surface, which is where the processes occur. This ensures that a low dosage of the toxic component is sufficient to provide good analytical signal, addressing issues related to the toxicity of cadmium-based materials. In this context, layered inorganic solids such as montmorillonite (MMT) and other clays were found to be particularly suitable as solid support. ${ }^{24}$ Xie et al..$^{25}$ reported the facile synthesis of $\mathrm{CdTe} / \mathrm{MMT}$ nanocomposite films via charge interactions between the CdTe QDs and MMT platelets to fabricate optoelectronic devices. These authors used sodium montmorillonite (Na-MMT) and cetyltrimethylammoniummodified montmorillonite (CTA-MMT) to make CdTe/MMT nanocomposite films exhibiting highly enhanced photoluminescence (PL) intensity compared with $\mathrm{CdTe} /(\mathrm{Na}-\mathrm{MMT})$ nanocomposite films. The PL difference indicated that the modification with CTA provided an electrostatic interaction that favored the loading of CdTe QDs in the CTA-MMT, as well as the long chain of the CTA reduced the surface defects avoiding the aggregation of the QDs.

An alternative approach to CdTe QDs/MMT nanocomposites was reported by $\mathrm{Li}$ et al. ${ }^{26}$ based on nanocrystal intercalation into the interlayer space after expansion with bulky surfactant molecules. This lead to the occurrence of quantum confinement phenomenon, evidenced by the emission band displacement for higher energy when compared to the CdTe bulk emission band. The as-synthesized nanocomposites have higher PL intensity compared to isolated $5 \mathrm{~nm}$ CdTe QDs. Other promising materials are layered double hydroxides (LDHs), also known as hydrotalcites or anionic clays, which exhibit physical and chemical properties close to the properties of clays minerals. ${ }^{27}$ Regarding the use of LDH, Li et al..$^{28}$ prepared hybrid films through layer-by-layer deposition alternating CdTe QDs and Co-Al-LDH for 
applications as electrochemiluminescence resonance energy transfer (ERET) sensors to detect trinitrotoluene. Luminol sodium salt (3-AMS) was intercalated into the gallery of Co-Al-LDHs by hydrothermal synthesis prior to the hybrid synthesis. To the best of our knowledge, the strategy reported here for the aqueous synthesis of CdTe nanocrystals on the surface of layered double hydroxides (LDHs) to electrochemical detections is original. The deposition of CdTe QDs onto the external surface of the matrix may be advantageous by: (i) avoiding the coalescence of nanoparticles, preserving the surface available for charge transfer and (ii) favoring the diffusion of analyte molecules to reach the CdTe surfaces, which would be difficult in the case of QDs intercalated into the interlayer region. In the present work, we synthesized CdTe nanocrystals in situ in inorganic hydrotalcite matrices and applied the resulting hybrid material as a carbon paste electrode modifier to sensitively and selectively detect CPX.

\section{Experimental}

\section{Materials}

Hydrotalcite (LDH) was purchased from SigmaAldrich (São Paulo, Brazil, CAS No. 11097-59-9) with $\mathrm{MgO} / \mathrm{Al}_{2} \mathrm{O}_{3}=4$.0-5.0. Ciprofloxacin (Sigma-Aldrich, São Paulo, Brazil, 98\%), tellurium powder (Sigma-Aldrich, São Paulo, Brazil, 99.8\%), cadmium chloride hydrate (SigmaAldrich, São Paulo, Brazil, 98\%), 3-mercaptopropionic acid (MPA, Sigma-Aldrich, São Paulo, Brazil, 99\%), sodium borohydride (Dinâmica, Indaiatuba, Brazil, 98\%), ethyl alcohol (Neon, Suzano, Brazil, 99\%), acetic acid (Vetec, São Paulo, Brazil, 99.7\%), sodium phosphate monobasic monohydrate (Synth, Diadema, Brazil, 98\%), sodium phosphate dibasic anhydrous (Synth, Diadema, Brazil, 99\%), orthophosphoric acid (Synth, Diadema, Brazil, 85\%), boric acid (Reagen, Colombo, Brazil, 99.9\%), ascorbic acid (IMPEX, São Paulo, Brazil, P.A.), citric acid (QUIMEX, São Paulo, Brazil, P.A.), zinc acetate dihydrate (Synth, Diadema, Brazil, 99\%), iron(II) chloride tetrahydrate (Vetec, São Paulo, Brazil, 98\%), copper(II) nitrate (Dinâmica, Indaiatuba, Brazil, P.A.), graphite (SigmaAldrich, São Paulo, Brazil, 99.9\%), sodium hydroxide (CRQ, São Paulo, Brazil, 98\%) were used as received. All experiments were carried out using ultrapure Milli-Q water.

\section{Methods}

Preparation of CdTe nanocrystals in situ onto hydrotalcite

The method used here employs a Cd:Te:MPA molar ratio of 1.0:0.2:1.2 as adapted from Santos et al..$^{22}$ First,
$50 \mathrm{~mL}$ of an aqueous $0.1 \mathrm{~mol} \mathrm{~L}^{-1} \mathrm{CdCl}_{2}$ solution containing also $0.12 \mathrm{~mol} \mathrm{~L}^{-1} \mathrm{MPA}$ was prepared and the $\mathrm{pH}$ adjusted to 9 with $1 \mathrm{~mol} \mathrm{~L}^{-1} \mathrm{NaOH}$. An oxygen-free $\mathrm{NaHTe}$ solution was then prepared by adding $0.127 \mathrm{~g}$ solid Te to $5 \mathrm{~mL}$ water in a Schlenk flask, followed by dropwise addition of a $\mathrm{NaBH}_{4}$ solution $\left(2.5 \mathrm{~g} / 5 \mathrm{~mL}\right.$ water) under $\mathrm{N}_{2}$ flow with vigorous stirring at $40{ }^{\circ} \mathrm{C}$ for nearly $20 \mathrm{~min}$. The freshly prepared colorless NaHTe solution was injected into the $\mathrm{Cd}^{2+}$ precursor solution, immediately followed by addition of $1.00 \mathrm{~g}$ of the hydrotalcite. After matrix addition, the reaction media were heated under hydrothermal conditions in a $80 \mathrm{~mL}$ Teflon-lined stainless steel reactor filled up to $50 \mathrm{~mL}$, in an oven at $100{ }^{\circ} \mathrm{C}$ for $1 \mathrm{~h}$. After cooling to room temperature (around $25-28^{\circ} \mathrm{C}$ ), the resulting suspensions were centrifuged, washed with distilled water and dried in an oven at $50{ }^{\circ} \mathrm{C}$ for $4 \mathrm{~h}$. The obtained hybrid materials were nominated by $\mathrm{LDH} / \mathrm{QD}$.

\section{Electrochemical studies}

The electrochemical measurements were carried out using a PGSTAT 100/Autolab model potentiostat/ galvanostat. The differential pulse voltammetric experiments were performed in a one-compartment cell using a carbon paste working electrode, a platinum wire auxiliary electrode and $\mathrm{Ag} / \mathrm{AgCl}$ reference electrode, at room temperature. Solutions used in electrochemical measurements and in the detection procedures were prepared by dilution of a stock solution. CPE and chemically modified electrodes (MCPE) with LDH and LDH/QD were prepared daily according to 7:3 mass proportion between powder (graphite + modifier):mineral oil. After mixing the components and homogenizing for $20 \mathrm{~min}$ in an agate mortar, the pastes were placed into homemade polypropylene syringe electrodes with a diameter of 4 and $3 \mathrm{~mm}$ copper wire, to ensure electrical contact with carbon paste. By rotating the sleeve, the plunger could be made to extrude a used paste layer, which was sliced off to form a fresh paste surface and was made by hand-polishing on a weighing paper.

\section{Analytical procedure}

A $10^{-4}$ mol L-1 CPX stock solution was prepared and diluted with the supporting electrolyte to yield $2.5 \times 10^{-8}-1.2 \times 10^{-5} \mathrm{~mol} \mathrm{~L}^{-1}$ solutions. The CPX determinations using modified electrodes with different materials were carried out by differential pulse voltammetric analysis, adding $10.00 \mathrm{~mL}$ of electrolyte cell solution containing a known concentration of CPX. Parameters such as scan rate, $\mathrm{pH}$, supporting electrolyte and amount of modified in $\mathrm{CPE}$ electrodes and accumulation time were optimized. All measurements were performed at room temperature. 
Instrumentation

$\mathrm{N}_{2}$ adsorption isotherms were measured at $77 \mathrm{~K}$ using a NOVA 1200 QuantaChrome equipment. Surface area and pore volume were calculated using the BrunauerEmmett-Teller (BET) method, while the pore diameters were calculated using Barrett-Joyner-Halenda (BJH) expression. Fourier transform infrared (FTIR) spectra of $\mathrm{KBr}$ pellets were acquired using a Shimadzu IR Prestige-21 with $2 \mathrm{~cm}^{-1}$ resolution in the $4000-400 \mathrm{~cm}^{-1}$ range. Powder $\mathrm{X}$-ray diffraction (XRD) patterns for materials were measured using a Empyrean (PANalytical) with $\mathrm{CuK} \alpha$ (1.5418 $\AA$ ) operating at $40 \mathrm{kV}$ and $40 \mathrm{~mA}$ in the $5.0-65^{\circ}$ range in $2 \theta$. Diffuse reflectance UV-Visible absorption spectra were measured for powdered samples using an Ocean Optics HR2000 instrument coupled to an optical fiber and an integrating sphere. PL spectra for powdered samples were measured in a spectrofluorimeter from Jasco (FP-8600), exciting the samples at $350 \mathrm{~nm}$. Transmission electron microscopy (TEM) images were obtained using a Jeol 2100 microscope operating at 200 kV. Samples were prepared by dropping isopropyl alcohol suspensions onto 400 mesh carbon-coated copper grids and allowing drying under ambient atmosphere.

\section{Results and Discussion}

\section{Characterization of materials}

XRD patterns obtained for LDH and LDH/QD samples can be found in Figure 1. XRD data for LDH sample show peaks at $2 \theta$ of $11.62^{\circ}, 23.37^{\circ}, 34.87^{\circ}$, corresponding to the (003), (006) and (009) basal peaks and characterizing the layered structure of hydrotalcite type compounds. ${ }^{29}$ No shifts in the positions of LDH basal planes were observed after CdTe deposition, suggesting that most of nanocrystals were formed onto the external surface, although the presence of few intercalated particles cannot be ruled out. Finally the presence of a weak reflection at $2 \theta=23.37^{\circ}$ suggests the formation of wurtzite CdTe phase. ${ }^{30}$ Additional peaks from CdTe nanocrystals could not be clearly identified owing to the intensity of the LDH crystallographic peaks. In order to confirm the presence of CdTe, a measurement of lattice spacings was carried out from high-resolution transmission electron microscopy (HRTEM) image (Figure S1, Supplementary Information (SI) section), which indicates a wurtzite crystal structure. ${ }^{31}$

The infrared spectra of LDH and LDH/QD (Figure 2a) are similar to each other owing to the prevalence of $\mathrm{LDH}$ bands. The broad and intense band at 3481-3450 $\mathrm{cm}^{-1}$ can be assigned to $\mathrm{OH}$ stretching from extrinsic water molecules as well as intra- and interlamellar hydroxyl

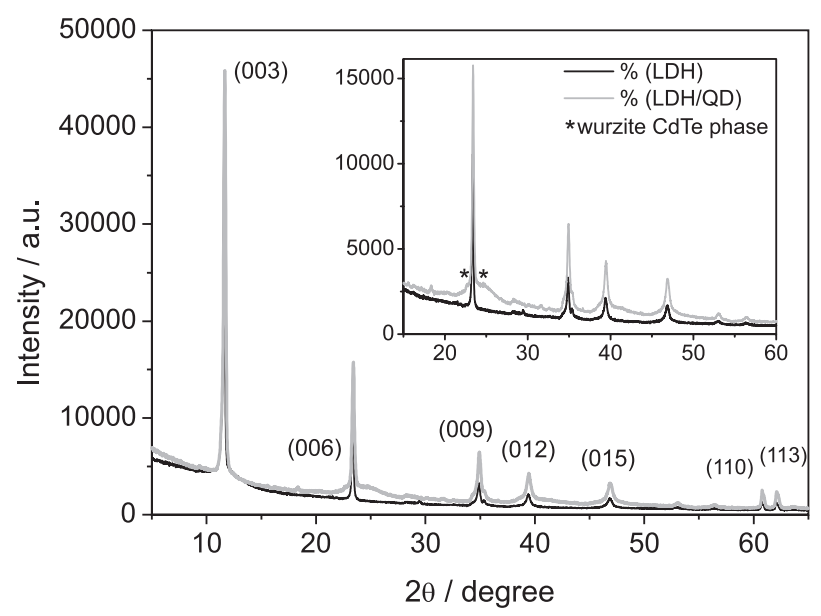

Figure 1. X-ray diffraction patterns of LDH and LDH/QD samples. The insertion evidences the region of the crystallographic baseline change between LDH and LDH/QD.

groups. Bands at 3075-2925 $\mathrm{cm}^{-1}$ are typical of hydrogen bonds between water molecules and the carbonate anion, while vibrations at $1572-1537 \mathrm{~cm}^{-1}$ are due to the bending mode of water. Bands from 1431-1371 $\mathrm{cm}^{-1}$ are related to the $\mathrm{C}-\mathrm{O}$ stretching vibrations from $\mathrm{CO}_{3}^{2-}$ anions. An interesting feature is that the $1371 \mathrm{~cm}^{-1}$ band is stronger for the LDH/QD hybrid than for pristine LDH, suggesting a reorganization of $\mathrm{CO}_{3}{ }^{2-}$ anions due to the absorption of CdTe nanocrystals. A shoulder at $933 \mathrm{~cm}^{-1}$ is better defined in the spectrum of the hybrid material, evidencing that the symmetrical stretching mode of the carbonate ion was probably activated by symmetry loss. ${ }^{32}$ Bands at $813-785 \mathrm{~cm}^{-1}$ correspond to out of plane deformation mode from carbonate ions. Absorptions in the $669-455 \mathrm{~cm}^{-1}$ range refer to $\mathrm{O}-\mathrm{M}-\mathrm{O}, \mathrm{M}-\mathrm{O}-\mathrm{M}$ and $\mathrm{M}-\mathrm{OH}$ vibration modes (where $\mathrm{M}$ is $\mathrm{Mg}$ or $\mathrm{Al}$ ). $\mathrm{Cd}-\mathrm{Te}$ stretching modes are expected near $170 \mathrm{~cm}^{-1},{ }^{33,34}$ thus outside the observed region. Evidences of the presence of MPA-capped CdTe nanocrystals are suggested in Figure $2 \mathrm{~b}$. The spectrum of pristine LDH shows bands at 1540 and $1362 \mathrm{~cm}^{-1}$ and, after CdTe formation, the relative intensities change significantly and both bands shift to positions close to values described to MPA bands. In a previous work, ${ }^{22}$ we prepared MPA-capped CdTe nanocrystals in situ into MCM-41 mesoporous silica and observed MPA-related bands in the FTIR spectrum of the hybrid material at 1560 and $1400 \mathrm{~cm}^{-1}$ (assigned, respectively, to asymmetric and symmetric COO- stretching).

Photoluminescence spectra for LDH and LDH/QD samples are shown in Figure 3a. LDH does not have any luminescence properties, while LDH/QD shows an emission band centered at $537 \mathrm{~nm}$ assigned to radiative recombination of electron-hole pairs formed upon electron photoexcitation. Full width at half maximum (FWHM) 

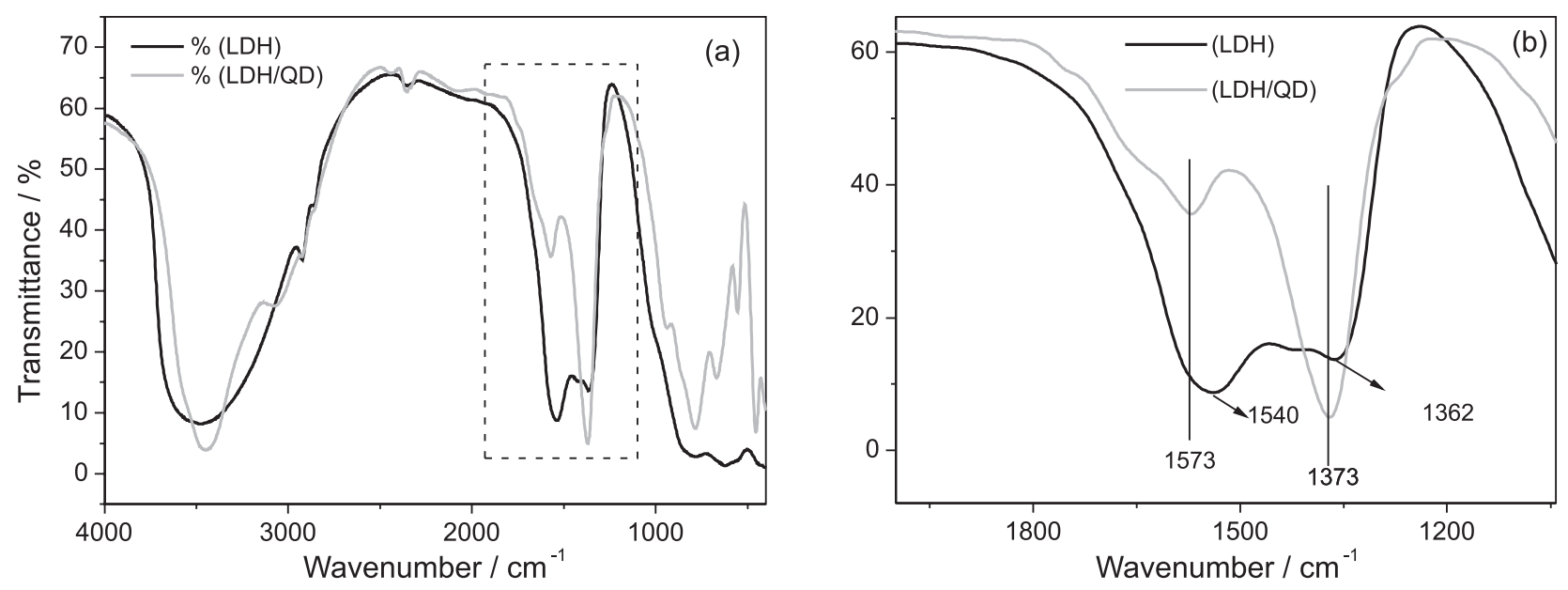

Figure 2. (a) FTIR spectra of LDH and LDH/QD samples; (b) zoom of the region within the rectangle in (a).

was $57.6 \mathrm{~nm}$, consistent with exciton recombination. The band observed is blue shifted in comparison to bulk CdTe $(841 \mathrm{~nm})$ and evidences the presence of nanocrystals, as predicted by the so-called quantum confinement effect. ${ }^{35}$ In simple terms, the band gap energy of the semiconductor increases with the decrease in nanocrystal size. The UV-Vis absorption spectrum of the LDH/QD sample (Figure $3 b$ ) shows a broad and asymmetric band from $330-620 \mathrm{~nm}$, which is typical of a mixture of nanocrystals with different sizes. HRTEM images of LDH/QD sample (Figures 4a-c) show the typical platelet morphology of LDH matrix (Figure 4a). Observation of platelet borders in higher magnifications $(b, c)$ shows the presence of nearly spherical particles with distinct electronic contrast, with lattice fringes evidencing the crystalline character of the nanoparticles whose diameters are below $5 \mathrm{~nm}$.

The textural properties of LDH and LDH/QD samples were determined by nitrogen adsorption and desorption at $77 \mathrm{~K}$ (Table 1), showing values similar to previous literature reports. ${ }^{36}$ The LDH material had surface area, pore volume

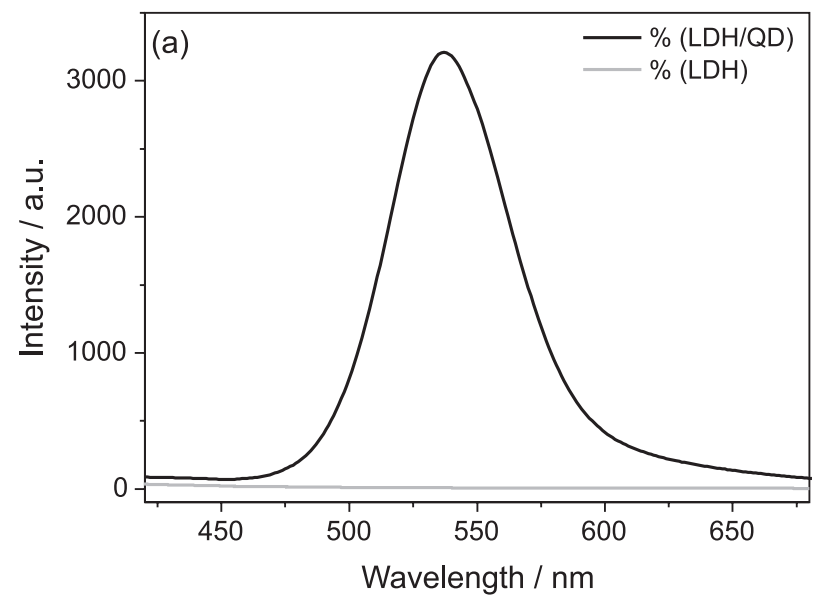

and pore diameter of $70 \mathrm{~m}^{2} \mathrm{~g}^{-1}, 0.1 \mathrm{~cm}^{3} \mathrm{~g}^{-1}$ and $4.0 \mathrm{~nm}$, respectively. On the other hand, the LDH/QD hybrid showed a significant increase of the surface area, $126 \mathrm{~m}^{2} \mathrm{~g}^{-1}$, probably due to the interparticle mesoporosity generated during the hydrothermal treatment of CdTe synthesis. ${ }^{32}$

\section{Electrochemical behavior of LDH/QD modified carbon paste electrode}

The LDH/QD hybrid material was electrochemically characterized by cyclic voltammetry in phosphate buffer at $\mathrm{pH} 7.0$, in the -1.5 to $1.5 \mathrm{~V}$ range ( $v s . \mathrm{Ag} / \mathrm{AgCl}$, Figure 5a). The cyclic voltammograms for CPE and MCPE-LDH (black and grey lines, respectively) did not show any electroactivity as expected. For the MCPE-LDH/QD (Figure 5a, dashed line) different redox peaks were observed, in good agreement to the behavior previously described for CdTe nanocrystals. ${ }^{37}$ The $\mathrm{A}_{1}$ oxidation peak $(+0.35 \mathrm{~V})$ can be assigned to surface defects related to dangling bonds, while the other two peaks, $\mathrm{A}_{2}(+1.20 \mathrm{~V})$

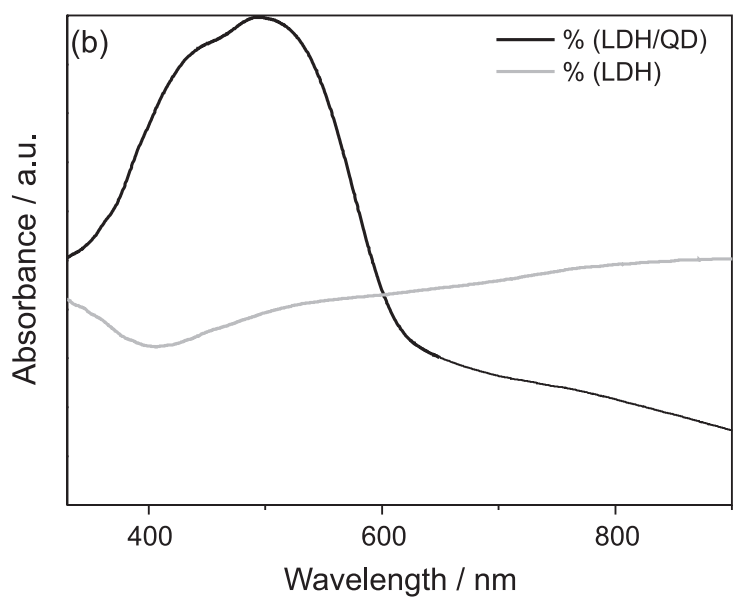

Figure 3. (a) Photoluminescence spectra and (b) diffuse reflectance absorption spectra of LDH and LDH/QD samples. 


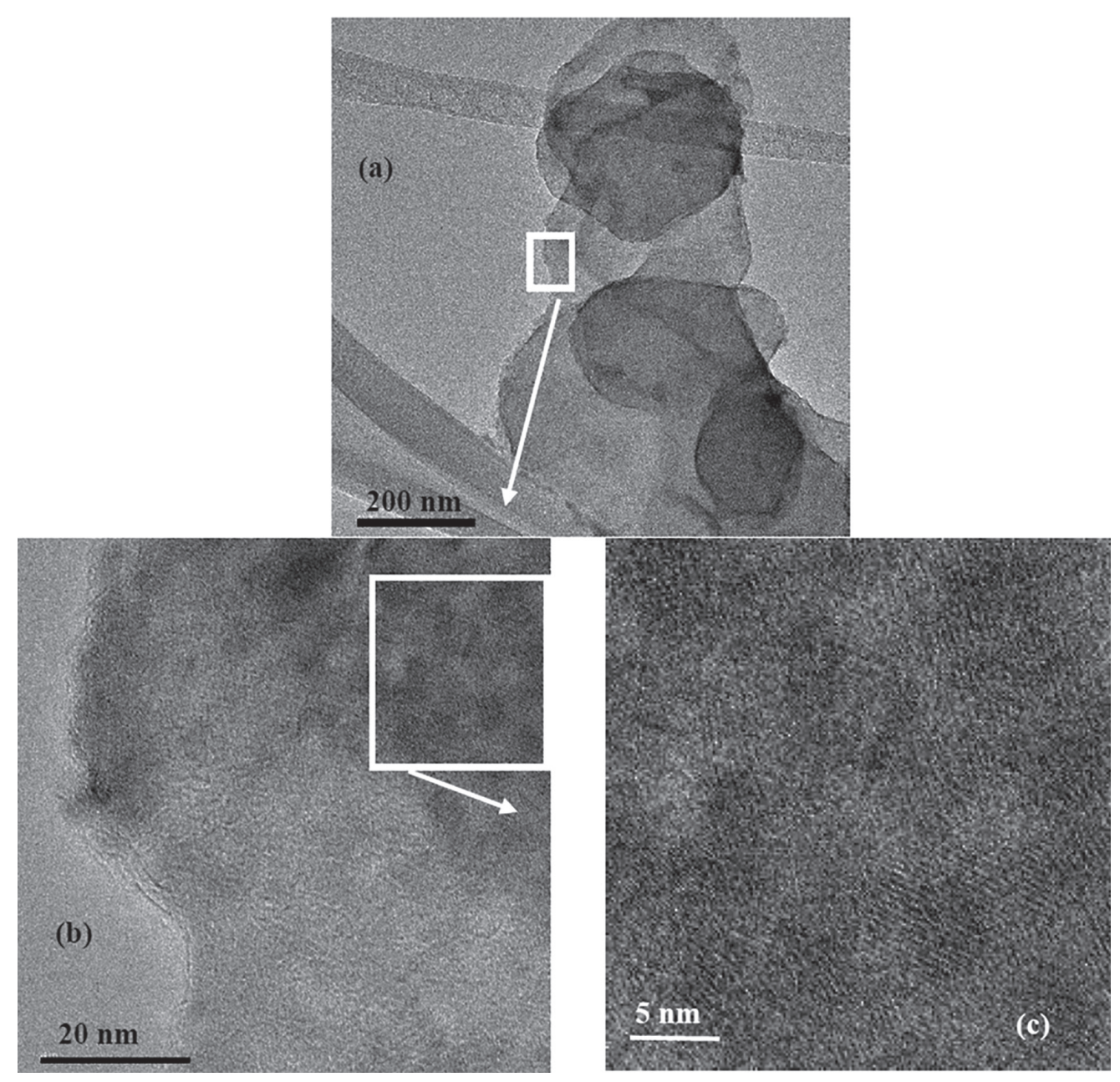

Figure 4. TEM images of LDH/QD sample with different magnifications. (a) Expanded view showing LDH platelets; (b, c) zoom of regions as indicated by the rectangular forms.

Table 1. Textural properties of materials

\begin{tabular}{lccc}
\hline Sample & $\begin{array}{c}\text { Surface area / } \\
\left(\mathrm{m}^{2} \mathrm{~g}^{-1}\right)\end{array}$ & $\begin{array}{c}\text { Pore diameter / } \\
\mathrm{nm}\end{array}$ & $\begin{array}{c}\text { Pore volume / } \\
\left(\mathrm{cm}^{3} \mathrm{~g}^{-1}\right)\end{array}$ \\
\hline LDH & 70 & 4.00 & 0.1 \\
LDH/QD & 126 & 4.00 & 0.3 \\
\hline
\end{tabular}

LDH: layered double hydroxide; QD: quantum dots.

and $\mathrm{C}_{1}(-1.32 \mathrm{~V})$ are assigned, respectively, to oxidation of the tellurium species in CdTe nanocrystals and the reduction of oxidation products of metallic nature $\left(\mathrm{CdTe}+6 \mathrm{OH}^{-} \rightarrow \mathrm{Cd}^{2+}+\mathrm{TeO}_{3}{ }^{2-}+3 \mathrm{H}_{2} \mathrm{O}+6 \mathrm{e}^{-}\right) .^{37}$

The performance of different electrodes (unmodified carbon paste electrode (CPE), LDH-modified CPE (MCPE-LDH) and LDH/QD-modified CPE (MCPE-LDH/ QD)) in the CPX determination by differential pulse voltammetry was compared (Figure 5b). CPE and MCPE-LDH showed oxidation peaks with lower current intensity, while MCPE-LDH/QD electrode exhibited the highest current intensity for CPX oxidation peak. This can be interpreted as a result of an increased electron transfer rate between the MCPE-LDH/QD and the analyte, facilitating the oxidation process. ${ }^{38}$

Relevant variables such as the electrolyte nature, $\mathrm{pH}$ value, electrode composition, scan rate and accumulation time were optimized in order to improve the electrochemical response (Figures S2-S6, SI section). All optimizations were carried out in the presence of $5.0 \times 10^{-6} \mathrm{~mol} \mathrm{~L}^{-1} \mathrm{CPX}$. The $\mathrm{pH}$ effect was evaluated using Britton-Robinson (BR) buffer in the 2-10 range, showing that the maximum anodic peak current occurs at $\mathrm{pH}$ 6. Ciprofloxacin is a polar compound with $\mathrm{p} K_{\mathrm{a}}$ values of 6.2 and 8.8 , thus the molecular charge is $\mathrm{pH}$ dependent. In acidic conditions, the $\mathrm{H}_{3} \mathrm{O}^{+}$excess may interfere in the protonation/deprotonation equilibrium, possibly masking electrochemical signals related to redox reactions, whilst strongly alkaline $\mathrm{pH}$ can compromise the electrochemical response due to degradation effect. ${ }^{39}$ Phosphate and BR buffers (both at $\mathrm{pH}$ 6) were tested in order to evaluate the influence of the support electrolyte, 

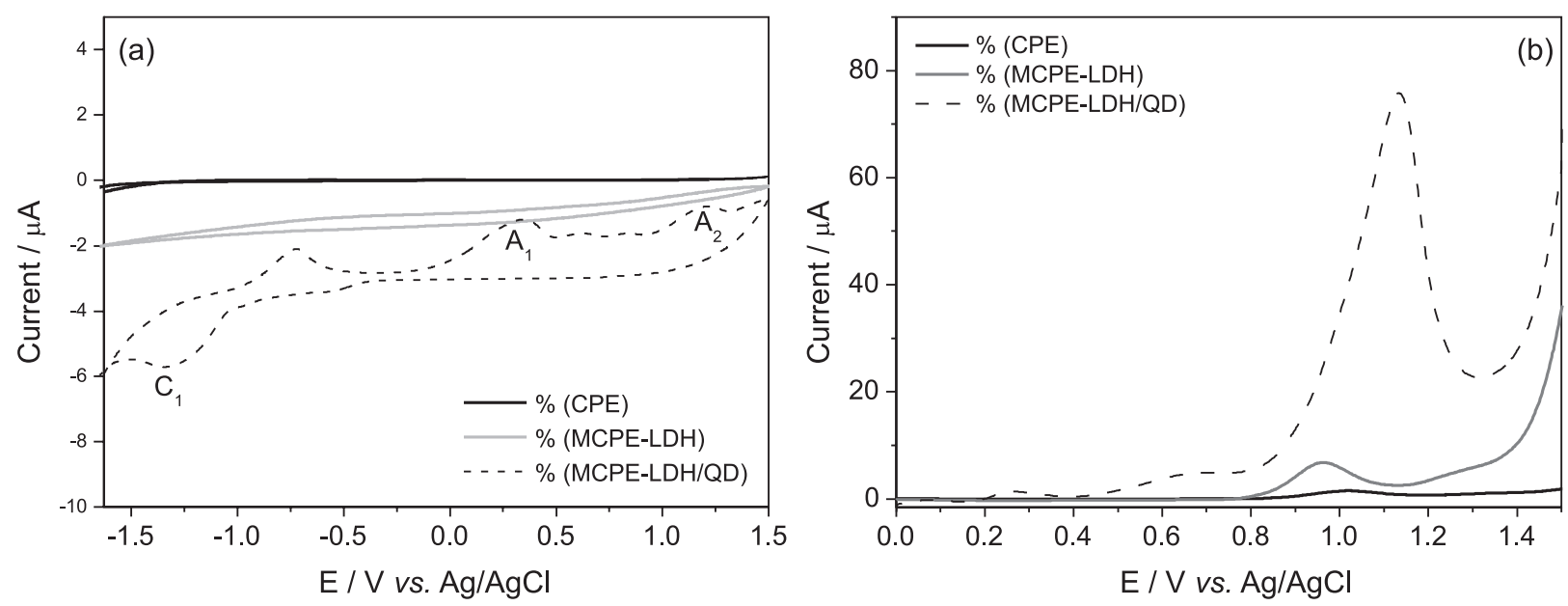

Figure 5. (a) Cyclic voltammograms of CPE, MCPE-LDH and MCPE-LDH/QD in phosphate buffer (pH 7.0), scan rate $20 \mathrm{mV} \mathrm{s}^{-1}$; (b) differential pulse voltammograms of CPE, MCPE-LDH and MCPE-LDH/QD in the presence of $5.0 \times 10^{-6} \mathrm{~mol} \mathrm{~L}^{-1}$ of CPX. The experimental conditions were phosphate buffer ( $\mathrm{pH} 7.0$ ) (a) and BR buffer ( $\mathrm{pH} 7.0$ ) (b), $300 \mathrm{~s}$ accumulation time and scan rate of $20 \mathrm{mV} \mathrm{s}^{-1}$.

with BR buffer showing the better results. The effect of $\mathrm{LDH} / \mathrm{QD}$ content on the voltammetric response was investigated using carbon slurries prepared with 0 to $30 \%$ $(\mathrm{m} / \mathrm{m})$ of modifier, observing the best results with $20 \%$. The influence of the scanning rate $(5,10,15,20$ and $25 \mathrm{mV} \mathrm{s}^{-1}$ ) and accumulation times (from 30 to $360 \mathrm{~s}$ ) allowed us to choose, respectively, $20 \mathrm{mV} \mathrm{s}^{-1}$ and $300 \mathrm{~s}$ as optimum conditions.

Analytical curve, interference studies and application in pharmaceutical form

The analytical curve (Figure 6a) was determined from differential pulse voltammetry (Figure 6 b) evidencing a linear behavior (coefficient of determination $\left(\mathrm{R}^{2}\right)=0.995$ ) for CPX concentrations in the $2.5 \times 10^{-8}-1.2 \times 10^{-5} \mathrm{~mol} \mathrm{~L}^{-1}$ range. The resulting equation was $\mathrm{I}_{\mathrm{p}, \mathrm{a}}(\mu \mathrm{A})=3.00[\mathrm{CPX}]-7.00 \times 10^{-5}$, where $\mathrm{I}_{\mathrm{p}, \mathrm{a}}$ refers to the anodic peak current, while [CPX] is the concentration of ciprofloxacin. The LOD was found to be $4.2 \times 10^{-8} \mathrm{~mol} \mathrm{~L}^{-1}$ (3.3 times the signal blank/slope) and limit of quantification (LOQ) was $1.3 \times 10^{-7} \mathrm{~mol} \mathrm{~L}^{-1}$ (ten times the signal blank/slope). A comparison of the efficiency of other modified electrodes reported for the determination of $\mathrm{CPX}^{40-44}$ (Table 2) shows that the electrode obtained here is among the most sensitive ones. The simple preparation procedure of the working electrode and the evident low limit of detection make the MCPE-LDH/QD a promising working electrode in voltammetric detection of analytes such as CPX. The modified electrode was stored at $4{ }^{\circ} \mathrm{C}$, keeping the response at $95 \%$ so far of its initial value, suggesting thet the MCPE-LDH/QD electrode is significantly stable.

In order to get information about the selectivity of MCPE/LDH-QD for CPX, an interference study was carried out in the presence of potential interferers $\left(\mathrm{Zn}^{2+}, \mathrm{Fe}^{2+}\right.$, $\mathrm{Cu}^{2+}$, citric acid and ascorbic acid) using $0.1: 1 ; 1: 1 ; 10: 1$ interferer:CPX ratios (Table 3). The CPX signal decreased in the presence of $\mathrm{Zn}^{2+}, \mathrm{Fe}^{2+}$ and $\mathrm{Cu}^{2+}$, with negligible effects for the low interferer concentrations. On the other hand, both citric and ascorbic acids interfered positively in CPX determination, since the current intensity increased slightly. A relative standard deviation (RSD) of $3.0 \%$ was found for CPX determination, indicating a remarkable reproducibility and precision, with $94 \%$ of recovery.

The method developed here was also applied to determine CPX in commercial $500 \mathrm{mg}$ tablets using a multiple standard addition approach. A certain weight of the tablet, milled and homogenized, was dissolved in ultrapure Milli-Q water. In a series of measurements, a fixed volume of sample solution was transferred to the electrochemical cell, followed by addition of increasing volumes of the standard solution and then diluted to a fixed volume before measurement. The resulting curve is shown in Figure $6 \mathrm{c}$ with good linear behavior and the result obtained $(495 \mathrm{mg}$ ) is in agreement to the declared CPX content.

\section{Conclusions}

The formation of CdTe nanocrystals supported onto the surface of layered double hydroxide (LDH) was evidenced by the absorption and emission spectroscopies as well as the electrochemical characterization. Particularly, emission spectroscopy data evidenced the quantum confined behavior of the nanocrystals obtained, confirmed by HRTEM images. The MCPE/LDH-QD electrode showed superior sensitivity in the detection of ciprofloxacin when compared to the CPE and MCPE/LDH electrodes. The developed 

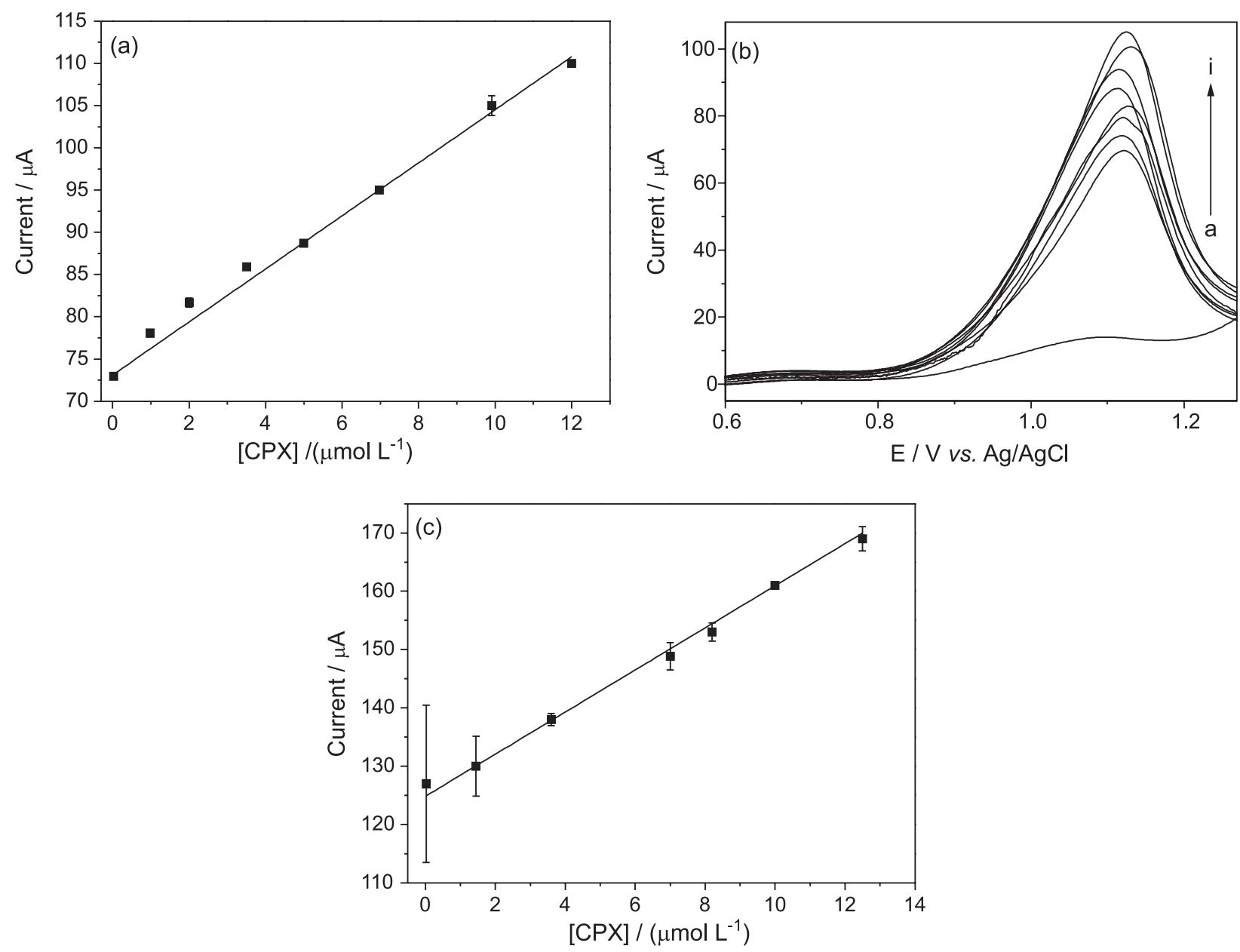

Figure 6. (a) Analytical curve obtained from the anodic peak currents for the CPX standard solutions; (b) differential pulse voltammograms obtained with MCPE-LDH/QD in blank solutions and in different CPX concentrations from $2.5 \times 10^{-8}$ to $1.2 \times 10^{-5} \mathrm{~mol} \mathrm{~L}^{-1}$; (c) analytical curve obtained from the anodic peak currents for the standard addition method used for determination of CPX in commercial tablets.

Table 2. Comparison of the efficiency of some modified electrodes used in the determination of CPX

\begin{tabular}{|c|c|c|c|}
\hline Electrode & Linear range / $\left(\mathrm{mol} \mathrm{L}^{-1}\right)$ & Limit of detection / $\left(\mathrm{mol} \mathrm{L}^{-1}\right)$ & Reference \\
\hline GCPE & $1.0 \times 10^{-8}$ to $7.5 \times 10^{-7}$ & $3.3 \times 10^{-8}$ & 40 \\
\hline GNs modified electrode & $5.0 \times 10^{-7}$ to $2.0 \times 10^{-4}$ & $2.0 \times 10^{-8}$ & 41 \\
\hline $\mathrm{Co} / \mathrm{TiO}_{2}$ modified carbon paste electrode & $1.0 \times 10^{-7}$ to $7.0 \times 10^{-4}$ & $3.0 \times 10^{-8}$ & 42 \\
\hline CPE modified with MWCNTs & $10^{-5}$ to $10^{-2}$ & $7.9 \times 10^{-6}$ & 1 \\
\hline Graphene-modified glassy carbon electrode & $1.0 \times 10^{-7}$ to $1.0 \times 10^{-4}$ & $1.0 \times 10^{-7}$ & 43 \\
\hline Heavily boron doped diamond electrode & $1.5 \times 10^{-7}$ to $2.1 \times 10^{-6}$ & $5.0 \times 10^{-8}$ & 44 \\
\hline Graphene-modified electrode & $1.0 \times 10^{-7}$ to $1.0 \times 10^{-5}$ & $5.9 \times 10^{-8}$ & 10 \\
\hline LDH/QD & $2.5 \times 10^{-8}$ to $1.2 \times 10^{-5}$ & $4.2 \times 10^{-8}$ & this work \\
\hline
\end{tabular}

GCPE: glassy carbon paste electrode; GNs: gold nanoparticles; MWCNT: multi-walled carbon nanotube; LDH/QD: layered double hydroxide/quantum dots.

Table 3. Variation of the peak current for the MCPE-LDH/QD when evaluated in the presence of interferers

\begin{tabular}{lccccc}
\hline \multirow{2}{*}{ Interferer] $/(\mu \mathrm{mol} \mathrm{L})^{-1}$} & \multicolumn{5}{c}{ Peak current in the presence of interferers / \% } \\
\cline { 2 - 6 } & Citric acid & Ascorbic acid & $\mathrm{Fe}^{2+}$ & $\mathrm{Cu}^{2+}$ & 79 \\
\hline 0.1 & 104 & 104 & 82 & 75 & 80 \\
1.0 & 106 & 107 & 80 & 71 & 79 \\
10 & 110 & 110 & 79 & 75 \\
\hline
\end{tabular}


methodology proved to be efficient for the detection of CPX in ciprofloxacin $500 \mathrm{mg}$ tablets, in agreement with the declared value.

\section{Supplementary Information}

Supplementary data are available free of charge at http://jbcs.sbq.org.br as PDF file.

\section{Acknowledgments}

The authors are grateful to Brazilian funding agencies Fapitec, FINEP, CNPq and CAPES for their financial support. The authors also thank LNNano-CNPEM (Campinas, Brazil) for the use of the JEOL JEM-2100F TEM microscope. L. P. C. and I. F. G. are grateful to CNPq (grants 311461/2017-4 and 304306/2016-9).

\section{References}

1. Abdel-Haleem, F. M.; Rizk, M. S.; Badr, I. H. A.; Electroanalysis 2017, 29, 1172 .

2. Tavares, W.; Antibióticos e Quimioterápicos para o Clínico, $3^{\text {a }}$ ed.; Atheneu: São Paulo, 2014.

3. Pham, T. S. H.; Mahon, P. J.; Lai, G.; Yu, A.; Electroanalysis 2018, 30, 2185.

4. Wei, R. C.; Ge, F.; Chen, M.; Wang, R.; J. Environ. Qual. 2012, $41,1481$.

5. Dewitte, B.; Dewulf, J.; Demeestre, K.; Van De Vyvere, V.; De Wispelaere, P.; Van Langenhive, H.; Environ. Sci. Technol. 2008, 42, 4889.

6. Larsson, D. J.; de Pedro, C.; Paxeus, N.; J. Hazard. Mater. 2007, 148, 751.

7. Riaz, L.; Mahmood, T.; Kamal, A.; Shafqat, M.; Rashid, A.; Environ. Toxicol. Pharm. 2017, 52, 14.

8. Ezelarab, H. A. A.; Abbas, S. H.; Hassan, H. A.; Abuo-Rahma, G. E. A.; Arch. Pharm. (Weinheim, Ger.) 2018, 351, e1800141.

9. Owens, R. C.; Ambrose, P.; Clin. Infect. Dis. 2005, 41, S144.

10. Shan, J.; Liu, Y.; Li, R.; Wu, C.; Zhu, L.; Zhang, J.; J. Electroanal. Chem. 2015, 738, 123.

11. Zhang, Y.; Cai, X.; Lang, X.; Qiao, X.; Li, X.; Chen, J.; Environ. Pollut. 2012, 166, 48.

12. Tan, Y.; Guo, Y.; Gu, X.; Gu, C.; Environ. Sci. Pollut. Res. Int. 2015, 22, 609.

13. Huet, A. C.; Delahaut, P.; Fodey, T.; Haughey, S. A.; Elliott, C.; Weigel, S.; TrAC, Trends Anal. Chem. 2010, 29, 1281.

14. Montes, R. H.; Marra, M. C.; Rodrigues, M. M.; Richter, E. M.; Muñoz, R. A.; Electroanalysis 2014, 26, 432.

15. Fotouhi, L.; Alahyari, M.; Colloids Surf., B 2010, 81, 110.

16. Garbellini, G. S.; Rocha-Filho, R. C.; Fatibello-Filho, O.; Anal. Methods 2015, 7, 3411.
17. Shan, J.; Li, R.; Yan, K.; Zhu, Y.; Zhang, J.; Sens. Actuators, B 2016, 237, 75 .

18. Zhao, W.-W.; Wang, J.; Zhu, Y.-C.; Xu, J.-J.; Chen, H.-Y.; Anal. Chem. 2015, 87, 9520.

19. Martins, M. A.; Trindade, T.; Quim. Nova 2012, 35, 1434.

20. Sobrova, P.; Ryvolova, M.; Hubalek, J.; Adam, V.; Kizek, R.; Int. J. Mol. Sci. 2013, 14, 13497.

21. Beitollahi, H.; Hamzavi, M.; Torkzadeh-Mahani, M.; Shanesaz, M.; Maleh, H. K. A.; Electroanalysis 2015, 27, 524.

22. Santos, J. C.; Matos, C. R. S.; Pereira, G. B. S.; Santana, T. B. S.; Souza Jr., H. O.; Costa, L. P.; Sussuchi, E. M.; Souza, A. M. G. P.; Gimenez, I. F.; Microporous Mesoporous Mater. 2016, $221,48$.

23. Pérez-Barrado, E.; Marsal, L. F.; Aguiló, M.; Cesteros, Y.; Díaz, F.; Pallarès, J.; Cucinotta, F.; Marchese, L.; Pujol, M. C.; Salagre, P. P.; RSC Adv. 2016, 6, 104793.

24. Ontam, A.; Khaorapapong, N.; Ogawa, M.; J. Mater. Chem. 2012, 22, 20001.

25. Xie, H.-Y.; Yang, J.; Yang, S.-Y.; Wang, C.-F.; Chen, L.; Chen, S.; Mater. Lett. 2011, 65, 1669.

26. Li, H.; Liu, J.; Wang, K.; Yu, X.; Zuo, S.; Li, B.; Mater. Lett. 2013, 107, 284.

27. Fernández, L.; Borrás, C.; Mostany, J.; Scharifker, B.; Recent Adv. Electrochem. Res. 2012, 115.

28. Li, Z.; Zhou, Y.; Yan, D.; Wei, M.; J. Mater. Chem. C 2017, 5, 3473.

29. Liu, J.; Lv, G.; Gu, W.; Li, Z.; Tang, A.; Mei, L.; J. Mater. Chem. C 2017, 5, 5024.

30. Huang, L.; Lu, S.; Chang, P.; Banerjee, K.; Hellwarth, R.; Lu, J. G.; Nano Res. 2014, 7, 228.

31. Wang, R.; Ouyang, J.; Nikolaus, S.; Brestaz, L.; Zaman, M. B.; Wu, X.; Leek, D.; Ratcliffe, C. I.; Yu, K.; Chem. Commun. 2009, 962.

32. Stoica, G.; Serrano, I. C.; Figuerola, A.; Ugarte, I.; Pacios, R.; Palomares, E.; Nanoscale 2012, 4, 5409.

33. Rebelo, M. M.; Cunha, M. V. P. O.; Correa, J. A. M.; Quim. Nova 2012, 35, 883.

34. Chagas, L. H.; Farias, S. B. P.; Leitão, A. A.; Diniz, R.; Quim. Nova 2012, 35, 1112.

35. Borse, V.; Sadawana, M.; Srivastava, R.; Proc. SPIE 2016, 9884, 988423.

36. Theiss, F. L.; Ayoko, G. A.; Frost, R. L.; Appl. Surf. Sci. 2016, $383,200$.

37. Khene, S.; Moeno, S.; Nyokong, T.; Polyhedron 2011, 30, 2162.

38. Matos, C. R. S.; Souza Jr., H. O.; Santana, T. B.; Candido, L. P. M.; Cunha, F. G. C.; Sussuchi, E. M.; Gimenez, I. F.; Microchim. Acta 2017, 184, 1755.

39. Ensafi, A. A.; Allafchian, A. R.; Mohammadzadeh, R.; Anal. Sci. 2012, 2, 705.

40. Kawde, A.-N.; Aziz, Md. A.; Odewunmi, N.; Hassan, N.; AlSharaa, A.; Arab. J. Sci. Eng. 2014, 39, 131. 
41. Xie, A.-J.; Chen, Y.; Luo, S.-P.; Tao, Y.-W.; Jin, Y.-S.; Li, W.-W.; Mater. Technol. 2015, 30, 362.

42. Shamsipur, M.; Gholivand, M. B.; Dehdashtian, S.; Feyzi, M.; Jafari, F.; Adv. Mater. Res. 2014, 829, 563.

43. Lim, S. A.; Ahmed, M. U.; Anal. Sci. 2016, 32, 687.
44. Radicova, M.; Behul, M.; Marton, M.; Vojs, M.; Bodor, R.; Redhhammer, R.; Stanova, A. V.; Electroanalysis 2017, 29, 1612.

Submitted: September 29, 2018 Published online: February 7, 2019 